\title{
Association between consumption of black tea and iron status in adult Africans in the North West Province: the THUSA study
}

\author{
P. S. Hogenkamp ${ }^{1,2}$, J. C. Jerling ${ }^{1 *}$, T. Hoekstra ${ }^{1}$, A. Melse-Boonstra ${ }^{1,2}$ and U. E. MacIntyre ${ }^{3}$ \\ ${ }^{1}$ School of Physiology, Nutrition and Consumer Science, North-West University, Private Bag X6001, Potchefstroom 2520, \\ South Africa \\ ${ }^{2}$ Division of Human Nutrition, Wageningen University and Research Centre, Po Box 8129, 6700 EV Wageningen, The Netherlands \\ ${ }^{3}$ Institute for Human Nutrition, Po Box 168, University of Limpopo, Medunsa, 0204, South Africa
}

(Received 28 March 2007 - Revised 19 November 2007 - Accepted 20 November 2007 - First published online 14 February 2008)

The association between black tea consumption and iron status was investigated in a sample of African adults participating in the cross-sectional THUSA (Transition and Health during Urbanization of South Africans) study in the North West Province, South Africa. Data were analysed from 1605 apparently healthy adults aged 15-65 years by demographic and FFQ, anthropometric measurements and biochemical analyses. The main outcome measures were $\mathrm{Hb}$ and serum ferritin concentrations. No associations were seen between black tea consumption and concentrations of serum ferritin (men $P=0.059$; women $P=0.49$ ) or $\mathrm{Hb}$ (men $P=0.33$; women $P=0.49$ ). Logistic regression showed that tea consumption did not significantly increase risk for iron deficiency (men: OR 1.36; $95 \%$ CI 0.99, 1.87; women: OR 0.98; $95 \%$ CI 0.84, 1.13) nor for iron deficiency anaemia (men: OR 1.28; $95 \%$ CI 0.84, 1.96; women: OR 0.93; $95 \%$ CI 0.78, 1.11). Prevalence of iron deficiency and iron deficiency anaemia was especially high in women: 21.6 and $14.6 \%$, respectively. However, the likelihood of iron deficiency and iron deficiency anaemia was not significantly explained by tea consumption in sub-populations which were assumed to be at risk for iron deficiency. Regression of serum ferritin levels on tea consumption in women $\leq 40$ years, adults with a daily iron intake $\leq 5.80 \mathrm{mg}$ and adults with ferritin levels $\leq 26.60 \mu \mathrm{g} / \mathrm{l}$, respectively, showed $P$ values in the range of $0 \cdot 28-0 \cdot 88$. Our findings demonstrate that iron deficiency and iron deficiency anaemia is not significantly explained by black tea consumption in a black adult population in South Africa. Tea intake was also not shown to be related to iron status in several sub-populations at risk for iron deficiency.

Black tea: Iron deficiency anaemia: Ferritin: Haemoglobin

Poor iron status, resulting from a long-term negative iron balance, is a major problem affecting people globally ${ }^{(1)}$. Iron deficiency anaemia is highly prevalent in developing countries, especially among children and women. Dietary iron intake in these areas is low and does not meet requirements naturally. Apart from iron intake, iron status is also affected by other dietary factors, such as polyphenols from tea ${ }^{(2)}$. The assessment of the constituents in the diet that affect the bioavailability of iron will in theory help in correction of factors that could contribute to iron deficiency.

After water, tea is the most popular consumed beverage worldwide with an average intake per capita of $120 \mathrm{ml} / \mathrm{d}^{(3)}$. Tea intake contributes significantly to the dietary intake of flavonoids. Apart from the potential protective role of flavanoids as antioxidants, these substances are assumed to affect negatively iron bioavailability by means of diminished solubility ${ }^{(4)}$.

Interventions with single meals have shown reduced uptake of iron from food when a test meal is accompanied by tea ${ }^{(5,6)}$ : iron absorption from test meals decreased from 12.1 (SD 4.5) $\%$ to 8.9 (SD 5.2) \% $(P<0.01)^{(6)}$. A limitation of this approach is that it does not reflect normal dietary conditions.
The association between tea and iron absorption was weaker when iron availability was assessed from the diet during a 2-week period than suggested by studies with single meals ${ }^{(7)}$. Furthermore, in a 16-week intervention trial investigating the possible differences between rooibos and black tea consumption on the iron status of black South African school children, no difference was shown between the effect of black tea in comparison with rooibos tea on markers of iron status ${ }^{(8)}$. The flavonoid content of black tea is approximately $20-30 \%$ higher when compared with that of herbal teas, and the addition of freshly boiled tap water to black tea leaves resulted in a concentration of $2 \mathrm{~g} / 100 \mathrm{ml}^{(9)}$.

In an overview of sixteen observational studies, a negative association between tea consumption and iron status was found in populations with a marginal iron status, which were defined as children and as menstruating women. All but two studies were carried out in Westernized populations where iron status is usually in the normal range ${ }^{(10)}$.

So far, very little is known about the effect of tea consumption on iron status in black populations. Vorster et al. ${ }^{(11)}$ described rural black children and women aged 16-65 years

Abbreviation: THUSA, Transition and Health during Urbanization of South Africans.

* Corresponding author: Dr J. C. Jerling, fax +27 18299 2464, email Johann.Jerling@nwu.ac.za 
as vulnerable groups for all levels of iron deficiency in South Africa, with usual iron intakes of less than $67 \%$ of the recommended amount (US RDA). Moreover, black tea appears to be one of the drinks most frequently consumed by children $^{(8,12)}$ and adults ${ }^{(13)}$ in South Africa and this might place the population at risk for iron deficiency.

Therefore, the aim of the present study was to further investigate the association between black tea consumption and iron status in a sample of black adults and in populations at risk for all levels of iron deficiency, living in the North West Province in South Africa.

\section{Materials and methods}

\section{Sample}

The THUSA (Transition and Health during Urbanization of South Africans) study was conducted from 1996 to 1998. For this cross-sectional study, 'apparently healthy' adults aged between 15 and 65 years were recruited from thirtyseven randomly selected sites in the North West Province of South Africa. Subjects with known diseases, pregnant and lactating women and subjects using chronic medication were excluded $^{(14)}$. In total, 1858 subjects were included in the THUSA study. For the present analysis we excluded subjects who were found to be infected with HIV ( $n$ 253), as this viral infection is assumed to be associated with iron accumulation and excessive iron storage. HIV disease progression might go along with increasing levels of serum ferritin and could therefore bias a possible correlation between tea consumption and iron status ${ }^{(15,16)}$. The remaining 1605 subjects were stratified by sex because of physiological differences in iron metabolism between men and women. Subjects were recruited from five levels of urbanization: $28.7 \%$ from deep rural areas; $15.6 \%$ from farms; $16.9 \%$ from informal housing areas; $27.8 \%$ from established urban townships; and $11.0 \%$ from 'upper' urban areas.

To ensure that volunteers were properly informed we provided all volunteers with written information explaining all aspects of the study. In addition and specifically for the benefit of illiterate volunteers, all information was also provided verbally in a language of their choice. All volunteers were given the opportunity to ask questions to clarify any aspects that were unclear. All volunteers signed an informed consent form and had the right to withdraw from the study at any time. The study was approved by the Medical Ethics Committee of the former Potchefstroom University for Christian Higher Education, now North-West University (Potchefstroom, South Africa).

\section{Measurements}

Data were collected by individual interviews conducted by researchers and trained fieldworkers. Anthropometric measurements and clinical and laboratory examinations were made. The THUSA study is described in detail elsewhere ${ }^{(14)}$.

A demographic questionnaire was used to obtain descriptive information on the study population. A validated quantitative FFQ was used to collect information on dietary intake $^{(17,18)}$. Quantities consumed were assessed using validated photographs of different portion sizes ${ }^{(19)}$, household measures and food models. Reproducibility of the FFQ was tested by a second administration of the FFQ to a randomly selected sub-sample of 144 volunteers $6-12$ weeks after the initial interview ${ }^{(18)}$. Relative validity of the FFQ was tested in a sub-sample of seventy-four volunteers by comparison to a $7 \mathrm{~d}$ weighed food record ${ }^{(19)}$. The reported nutrient intakes were analysed using a program (Food Finder ${ }^{\circledR}$ Medical Research Council, Tygerberg, South Africa) based on the South African Food Composition Tables. Since tea often means any hot drink in this culture, brand names were asked as well. Tea consumption was defined as the intake of black tea only. Milk and/or sugar added to tea were recorded separately.

Anthropometric measurements included height and weight, and BMI (in $\mathrm{kg} / \mathrm{m}^{2}$ ) was calculated for each participant. Haematocrit and $\mathrm{Hb}$ concentrations were measured in EDTA blood according to the centrifuge and cyanmethaemoglobin methods, respectively. Serum ferritin, transferrin and iron concentrations and total iron-binding capacity were determined using standard immunological, colorimetric and HPLC $\operatorname{methods}^{(14)}$.

\section{Statistical analysis}

Statistical analyses for the reproducibility and relative validation studies were done using the Statistica for Windows (version 5) software (Statsoft, Tulsa, OK, USA). Correlations between energy and nutrient intakes derived from the first and second administrations of the FFQ, and the FFQ and the average of intakes from the $7 \mathrm{~d}$ weighed records were tested using Spearman rank correlation coefficients, differences in mean intakes between administrations and methods were tested using the $t$ test for paired samples and the Bland-Altman method $^{(20)}$ was used to identify proportional bias and the limits of agreement. Detailed descriptions of the statistical analyses of the reproducibility and relative validity studies have been published elsewhere ${ }^{(17,18)}$.

SPSS software package version 14.0 for Windows (SPSS Inc., Chicago, IL, USA) was used to perform statistical analyses, and $P<0.05$ was considered statistically significant.

Mean values and standard deviations of descriptive variables and prevalence of iron deficiency and of iron deficiency anaemia were calculated. Variables that were not normally distributed were presented as geometric mean with $95 \%$ CI after applying log-transformation. Iron deficiency was defined as a serum ferritin level $<15 \mu \mathrm{g} / \mathrm{l}$, since iron stores are assumed to be depleted below these concentrations ${ }^{(1)}$. Anaemia was defined as occurrence of subnormal $\mathrm{Hb}$ levels according to the $\mathrm{WHO}$, i.e. $\mathrm{Hb}<12 \mathrm{~g} / \mathrm{dl}$ in non-pregnant adult women and $\mathrm{Hb}<13 \mathrm{~g} / \mathrm{dl}$ in men ${ }^{(1)}$. Iron deficiency anaemia was defined as a combination of anaemia and iron deficiency.

Serum ferritin and $\mathrm{Hb}$ concentrations across categories of black tea consumption, defined as household measures of $180 \mathrm{ml}$, were determined in a multivariate ANOVA, simultaneously correcting for known confounding variables. Prevalences of iron deficiency and iron deficiency anaemia across black tea consumption categories and OR for iron deficiency anaemia at each level of black tea consumption, with no tea intake as a reference, were calculated. A test for trend of the OR across the tea categories was done using a logistic 
regression model including the numbers of cups of black tea per tea consumption category as a continuous variable. The association between black tea consumption and either iron deficiency or iron deficiency anaemia was evaluated in multiple linear regression models, adjusting for age, BMI, smoking status, and alcohol and iron intake.

Likewise, the analysis was repeated for sub-populations 'at risk', defined as (1) women $\leq 40$ years; (2) subjects of both sexes with a low consumption of dietary iron, defined as the bottom quartile of iron intake $(\leq 5.8 \mathrm{mg} / \mathrm{d})$; and (3) subjects with a marginal iron status, defined as the bottom quartile of serum ferritin concentrations $(\leq 26.6 \mu \mathrm{g} / \mathrm{l})$.

\section{Results}

Complete demographic, dietary and physiological data were obtained from 1360 subjects. Demographic data of this population showed a mean household size of 6.0 and $41 \%$ of all the subjects were employed at the moment of data collection. The total monthly household income was assessed to be R1000 (approximately 110 euro) or less for $74 \%$ of the study population. Demographic factors, dietary intake and iron indicators of men and women are presented in Table 1. Significant differences between men and women were observed for mean values of $\mathrm{Hb}$, serum iron and serum ferritin concentrations, total iron-binding capacity levels, transferrin saturation and haematocrit. All mean values of indicators of iron status fell within normal ranges.

The results of the reproducibility for reported iron intakes showed a significant correlation coefficient of 0.3 (95\% CI $0.12,0.42$ ), a small non-significant difference mean iron intake $(1.2 \mathrm{mg} ; 95 \%$ CI $0.39,2.01)$ and weak, non-significant proportional bias $(r 0.1 ; 95 \% \mathrm{CI}-0.07,0 \cdot 26)$ between administrations of the $\mathrm{FFQ}^{(18)}$. Regarding relative validity, there was a weak non-significant correlation coefficient of 0.2 (95\% CI $-0.03,0.41)$ between iron intakes derived from the FFQ and the average of the intakes from the $7 \mathrm{~d}$ weighed record. There appeared to be slight, but not significant, underreporting of iron intakes on the FFQ compared to the average of the $7 \mathrm{~d}$ food record (difference (weighed record $\mathrm{FFQ})=0.5 \mathrm{mg} ; 95 \% \mathrm{CI}-0.6,1.6$ ), while the Bland-Altman method showed negligible proportional bias between the two methods $(r 0.1 ; 95 \% \mathrm{CI}-0 \cdot 07,0 \cdot 26)^{(20)}$.

In women, serum ferritin concentrations were positively correlated with $\mathrm{Hb}$ concentrations (Pearson correlation coefficient, $r 0 \cdot 26, P<0 \cdot 01)$. Dietary iron intake of women $(7.6 \mathrm{mg}$; $95 \%$ CI $7.3,7.8$ ) was low when compared to the estimated average requirement $(8.1 \mathrm{mg} / \mathrm{d}$ for women $19-50$ years; $5 \mathrm{mg} / \mathrm{d}$ for women $>50$ years according to US estimated average requirement $\left.{ }^{(21)}\right)$. Iron intake showed a weak negative correlation with black tea consumption in both men $(r-0.08$, $P=0.041)$ and women $(r-0.07, P=0.052)$. There was a strong positive correlation between iron and energy intake in both sexes (men $r 0.78$; women $r 0.82 ; P<0.05$ ), but black tea consumption was not significantly correlated with energy intake. Age, BMI and alcohol intake showed significant related to serum ferritin and $\mathrm{Hb}$ concentrations and were, except for BMI, positively correlated with tea consumption as well. Serum ferritin concentrations in both sexes were higher in smokers than in non-smokers and in women $\mathrm{Hb}$ concentrations were higher among smokers than among non-smokers $(P<0 \cdot 01)$.

Table 1. Characteristics of the subjects studied

\begin{tabular}{|c|c|c|c|c|c|c|}
\hline \multirow[b]{2}{*}{ Variable } & \multicolumn{3}{|c|}{ Men $(n 571) \dagger$} & \multicolumn{3}{|c|}{ Women $(n$ 789) $†$} \\
\hline & Mean & SD & $95 \% \mathrm{Cl}$ & Mean & SD & $95 \% \mathrm{Cl}$ \\
\hline Age (years) & $37 \cdot 7$ & $15 \cdot 7$ & & $38 \cdot 2$ & $14 \cdot 4$ & \\
\hline BMI $\left(\mathrm{kg} / \mathrm{m}^{2}\right)$ & $21 \cdot 0^{*}$ & $3 \cdot 8$ & & $27 \cdot 0$ & $6 \cdot 9$ & \\
\hline Snuff users (\% (n/total)) & $7 \cdot 8^{*}$ & 53/679† & & $19 \cdot 4$ & 178/918† & \\
\hline Smokers (\% (n/total)) & $46 \cdot 8^{\star}$ & 318/680† & & $24 \cdot 0$ & 221/920† & \\
\hline Packages smoked (packyears $\ddagger$ ) & $3 \cdot 0$ & & $1 \cdot 1,7 \cdot 0$ & $3 \cdot 0$ & & $0 \cdot 6,6 \cdot 4$ \\
\hline Total energy intake (kJ) & $9293 \cdot 6^{\star}$ & $3607 \cdot 8$ & & $7918 \cdot 8$ & $2973 \cdot 8$ & \\
\hline Energy from carbohydrates (\%) & $60 \cdot 7^{\star}$ & $10 \cdot 2$ & & $62 \cdot 1$ & $10 \cdot 0$ & \\
\hline Energy from fat (\%) & $24 \cdot 5^{\star}$ & $7 \cdot 9$ & & $26 \cdot 3$ & $7 \cdot 7$ & \\
\hline Energy from protein (\%) & $12 \cdot 2^{*}$ & $2 \cdot 4$ & & $12 \cdot 6$ & $2 \cdot 4$ & \\
\hline Total protein (g) & $64 \cdot 4^{*}$ & $22 \cdot 8$ & & $57 \cdot 2$ & $21 \cdot 2$ & \\
\hline Animal protein (g) & $28 \cdot 3^{*}$ & $15 \cdot 5$ & & $26 \cdot 4$ & $15 \cdot 5$ & \\
\hline Dietary iron (mg) & $8 \cdot 2^{*}$ & & $7 \cdot 9,8 \cdot 5$ & $7 \cdot 6$ & & $7 \cdot 3,7 \cdot 8$ \\
\hline Alcohol $(\mathrm{g})$ & $4 \cdot 6^{\star}$ & & $4 \cdot 0,5 \cdot 2$ & 1.5 & & $1.4,1.6$ \\
\hline Tea $(\mathrm{ml})$ & $56 \cdot 6^{\star}$ & & $45 \cdot 0,70 \cdot 0$ & $85 \cdot 1$ & & $70 \cdot 0,100 \cdot 0$ \\
\hline Tea $(\mathrm{ml}) \S$ & $220 \cdot 0^{\star}$ & & $0 \cdot 0,440 \cdot 0$ & $300 \cdot 0$ & & $31 \cdot 0,600 \cdot 0$ \\
\hline Non-tea consumers (\% (n/total)) & $29 \cdot 3^{\star}$ & $187 / 639 \dagger$ & & $23 \cdot 7$ & 210/886† & \\
\hline Haematocrit (\%) & $45 \cdot 2^{\star}$ & & $44 \cdot 9,45 \cdot 4$ & $41 \cdot 1$ & & $40 \cdot 8,41 \cdot 4$ \\
\hline $\mathrm{Hb}(\mathrm{g} / \mathrm{dl})$ & $13 \cdot 4^{*}$ & & $13 \cdot 2,13 \cdot 5$ & $12 \cdot 1$ & & $12 \cdot 0,12 \cdot 2$ \\
\hline Serum iron $(\mu g / l)$ & $16 \cdot 6^{\star}$ & & $15 \cdot 9,17 \cdot 3$ & $13 \cdot 2$ & & $12 \cdot 7,13 \cdot 8$ \\
\hline Total iron-binding capacity $(\mu \mathrm{g} / 100 \mathrm{ml})$ & $63 \cdot 9^{\star}$ & & $62 \cdot 9,64 \cdot 8$ & $68 \cdot 2$ & & $67 \cdot 4,69 \cdot 1$ \\
\hline Transferrin saturation (\%) & $26 \cdot 0^{\star}$ & & $29 \cdot 4,27 \cdot 2$ & $19 \cdot 3$ & & $18 \cdot 5,20 \cdot 1$ \\
\hline Serum ferritin $(\mu \mathrm{g} / \mathrm{l})$ & $107 \cdot 3^{\star}$ & & $98 \cdot 0,117 \cdot 4$ & $40 \cdot 7$ & & $37 \cdot 4,44 \cdot 3$ \\
\hline Iron deficiency $(\%(n /$ total $))$ & $6 \cdot 8^{\star}$ & 46/681† & & $21 \cdot 6$ & 199/920† & \\
\hline Iron deficiency anaemia (\% ( $n /$ total $))$ & $3 \cdot 2^{*}$ & $21 / 664 \dagger$ & & $14 \cdot 6$ & $128 / 877 \dagger$ & \\
\hline
\end{tabular}

Values were significantly different from those of the female group: ${ }^{*} P<0.05$.

† Data were completed for 1360 subjects; for some variables the mean is based on data of a larger number of subjects.

$\ddagger$ Packyears $=$ (number of cigarettes $\times$ number of years smoking) $/ 20$.

$\S$ Data presented as median and interquartile range. 
In trend-anaysis, unadjusted serum ferritin levels across black tea consumption categories (Fig. 1) showed a decreasing concentration of serum ferritin in tea-consuming men, but this pattern was not consistent across the highest two categories of black tea intake. No clear trend in serum ferritin levels across categories of tea intake was seen in women. Adjustment for age, BMI, alcohol and iron intake, and smoking status did not alter these trends (Table 2): for both sexes, no trend was shown for the relationship between black tea consumption and $\mathrm{Hb}$ (men $P=0.33$; women $P=0.49$ ) or serum ferritin (men $P=0.059$; women $P=0.49$ ).

OR were adjusted for age, BMI, alcohol and iron intake, and smoking status. Tea intake of $0 \mathrm{ml}$ was used as the reference category (Table 3). Except for black tea intake of $181-360 \mathrm{ml}$ in men, all OR for iron deficiency and iron deficiency anaemia showed broad confidence intervals without a trend across the tea consumption categories.

Multiple logistic regression with iron deficiency as a dependent variable and adjusted for confounders showed similar results: the relation between black tea consumption and status of iron deficiency was not significant in either men or women (men $P=0.056$; women $P=0.74$ ); similarly, iron deficiency anaemia was not significantly correlated to black tea consumption in either men or women (men $P=0.26$; women $P=0.42$ ).

Intake of iron did not show a significant correlation with status of iron deficiency or iron deficiency anaemia. Multiple logistic regression showed that only age and smoking status were predictive for iron deficiency in both sexes and for iron deficiency anaemia only in women.

In order to test the hypothesis that the association between black tea and iron status is only present in high-risk groups, analyses were repeated in three populations that we defined as 'at risk for iron deficiency': (1) women $\leq 40$ years (prevalence of iron deficiency (n/total): $29.8 \%$ (151/507)); (2) subjects of both sexes with a dietary iron intake $\leq 5.8 \mathrm{mg} / \mathrm{d}$ $(32.2 \%(75 / 233)$ of the women and $12.4 \%(18 / 145)$ of the men); and (3) men and women with serum ferritin levels $\leq 26.6 \mu \mathrm{g} / \mathrm{l}(53.2 \%(167 / 314)$ in women and $43.9 \%(29 / 66)$ in men). None of these at-risk populations showed significant differences in serum ferritin or $\mathrm{Hb}$ concentrations across tea consumption categories; linear regression with serum ferritin as dependent variable demonstrated no significant relation with black tea intake (Table 4). Using multiple logistic regression, adjusted for confounders, black tea consumption

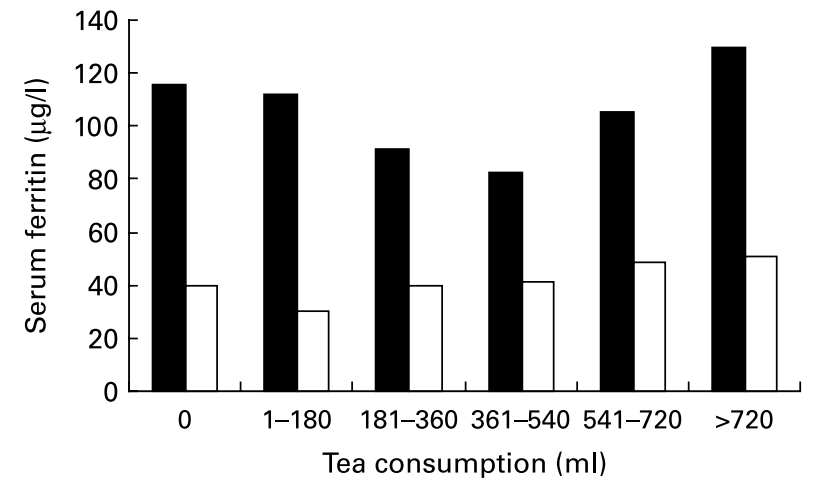

Fig. 1. Geometric means of unadjusted serum ferritin concentrations within tea consumption categories. $\mathbf{\square}$, Men; $\square$, women.

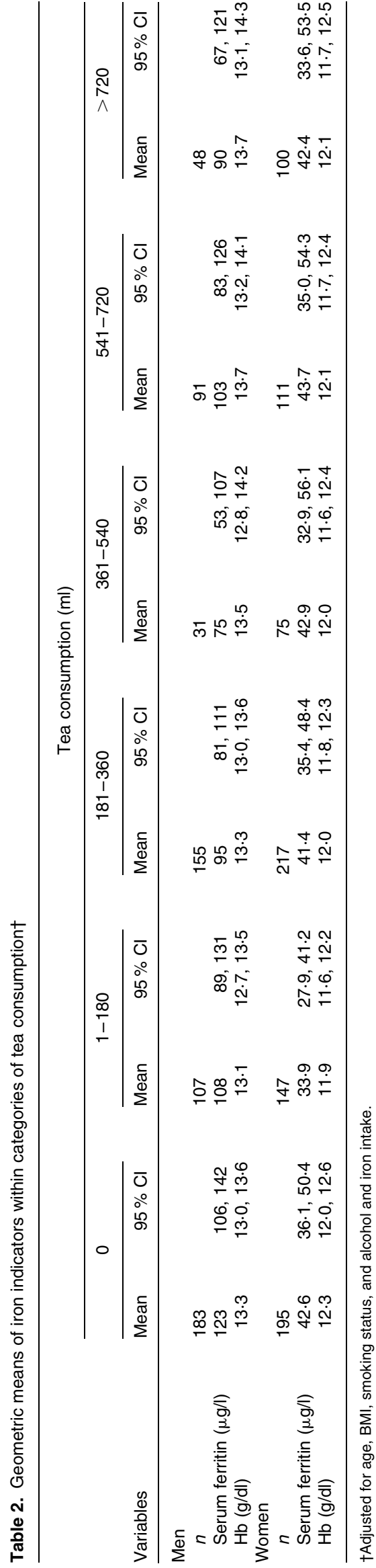


Table 4. Multiple linear regression of tea consumption and serum ferritin on tea consumption in different populations at risk $\dagger$

\begin{tabular}{lccc}
\hline Population & $\beta$ (tea intake) & $P$ & Adjusted $R^{2}$ \\
\hline Women $\leq 40$ years & -0.006 & 0.77 & 0.08 \\
Iron intake $\leq 5.80 \mathrm{mg}$ (men) & -0.007 & 0.84 & 0.25 \\
$\quad$ Iron intake $\leq 5.80 \mathrm{mg}$ (women) & 0.005 & 0.88 & 0.22 \\
$\quad$ Serum ferritin $\leq 26.60 \mu \mathrm{g} / \mathrm{l}$ & -0.040 & 0.28 & 0.02 \\
$\quad$ (men) & & & \\
$\quad$ Serum ferritin $\leq 26.60 \mu \mathrm{g} / \mathrm{l}$ & -0.011 & 0.55 & -0.01 \\
$\quad$ (women) & & &
\end{tabular}

†Adjusted for age, BMI, smoking status, and alcohol and iron intake.

showed no increased risk for iron deficiency or iron deficiency anaemia in any of these sub-populations (Table 5).

\section{Discussion}

In this large population of black African men and women we did not find consistent associations between black tea consumption and iron status. However, associations between black tea intake and serum ferritin concentration and between black tea intake and prevalence of iron deficiency in men were borderline significant and suggest a tendency for these associations. Age, sex and smoking status were the strongest predictor variables for iron status. Prevalence of both iron deficiency and iron deficiency anaemia was especially high in women. Iron stores were depleted in one of five women and this lack of iron was responsible for anaemia in $15 \%$ of the women.

The question of the effect of the addition of milk to tea on a number of physiological outcomes has been of interest for a number of years. It is known that proteins can bind to flavonoids $^{(22,23)}$ and it has been hypothesized that milk might have some functional effect on the ability of flavonoids to bind metals or act as antioxidants. A recent report suggests that milk protein could inhibit potential favourable effects of tea on flow-mediated dilation ${ }^{(24)}$. It has, however, been shown that the addition of milk to black tea has no effect on antioxidant activity ${ }^{(25-27)}$ and that the addition of milk to tea does not affect the bioavailability of flavonoids ${ }^{(28,29)}$. The most relevant work, however, was done by Hurrell et al. who studied the effects of different polyphenol-containing beverages on iron absorption from a bread meal in adult human subjects using the erythrocyte incorporation of radio-Fe as primary endpoint ${ }^{(30)}$ and showed that adding milk to tea has little or no influence on its iron inhibitory nature.

It is generally accepted that bioavailability of iron is influenced by a variety of dietary factors ${ }^{(4)}$, such as fibre, calcium, ascorbic acid and animal protein. Although experimental studies have shown that polyphenolic-containing liquids inhibit iron absorption ${ }^{(5,6,31)}$, we found that black tea consumption did not negatively affect either serum ferritin levels or iron status in this cross-sectional analysis. A similar conclusion was drawn from a study in the rural areas of China where even high levels ( $38 \mathrm{~g}$ dry weight/d) of black tea consumption were not correlated with iron status ${ }^{(32)}$. Serum ferritin concentrations and prevalence of iron deficiency in the present black African study population were in the same range as those found in studies investigating the relationship between tea intake and iron status in European populations ${ }^{(33,34)}$ and 
Table 5. Logistic regression of tea consumption and iron deficiency and iron deficiency anaemia in different populations at risk†

\begin{tabular}{|c|c|c|c|c|}
\hline \multirow[b]{2}{*}{ Population at risk } & \multicolumn{2}{|c|}{ Iron deficiency } & \multicolumn{2}{|c|}{ Iron deficiency anaemia } \\
\hline & OR & $95 \% \mathrm{Cl}$ & OR & $95 \% \mathrm{Cl}$ \\
\hline Women $\leq 40$ years & 1.02 & $0 \cdot 85,1 \cdot 22$ & 0.92 & $0 \cdot 75,1 \cdot 14$ \\
\hline Iron intake $\leq 5.80 \mathrm{mg}$ (men) & 0.99 & $0.99,1.00$ & 0.99 & $0.99,1.00$ \\
\hline Iron intake $\leq 5.80 \mathrm{mg}$ (women) & 1.00 & $0.99,1.00$ & 1.00 & $0.99,1.00$ \\
\hline Serum ferritin $\leq 26.60 \mu \mathrm{g} / \mathrm{l}$ (men) & $1 \cdot 40$ & $0.85,2 \cdot 29$ & $1 \cdot 32$ & $0.77,2 \cdot 26$ \\
\hline Serum ferritin $\leq 26.60 \mu \mathrm{g} / \mathrm{l}$ (women) & $1 \cdot 00$ & $0.81,1.23$ & 0.95 & $0.75,1.15$ \\
\hline
\end{tabular}

†Adjusted for age, BMI, smoking status, and alcohol and iron intake.

ferritin concentrations were in line with those in a population of rural Chinese women as well ${ }^{(32)}$.

From our regression models, adjusted for demographic and lifestyle variables, it can be concluded that black tea consumption as part of a complete diet is not a significant predictor of iron status, iron deficiency or iron deficiency anaemia, whereas sex, age and smoking status were the main determinants of iron status. Furthermore, iron intake was not significantly associated with iron status in the present study population.

The validity of reported nutrient intakes is always of concern in dietary intake studies. In the present study, while reported iron intakes were found to be reproducible, relative validity, on an individual level, as estimated from the Spearman rank correlation coefficient was found to be weak. Comparison of reported mean intakes and the Bland-Altman plot showed slight (but not significant) underreporting by the FFQ. Therefore, actual iron intakes may have been slightly higher than those reported in some subjects. Nevertheless, in light of the very weak association of iron status and iron intake it is unlikely that this difference would have led to different results.

Dietary iron in an absorbable form is essential for maintenance of an adequate iron status. However, considering the confounding variables, we did not find a significant relation between iron intake and iron status, which is in agreement with several other studies with a similar design ${ }^{(32,35,36)}$. Demographic factors, smoking status and menstrual blood loss in females are shown to be important determinants of iron status as well ${ }^{(34)}$.

The present results from this apparently healthy African population agree with the final statements of several other observational studies. Results of the National Health and Nutrition Survey in the USA showed that both iron intake and tea consumption as part of a varied diet were not significant determinants of iron deficiency anaemia after controlling for iron and ascorbic acid intake. However, both age and sex contributed to prediction of iron status ${ }^{(37)}$. Furthermore, the present findings are in line with an extended review of sixteen studies, almost all in Western populations ${ }^{(10)}$, and a review based on twelve observational studies in the $\mathrm{UK}^{(38)}$ on the association between tea consumption and iron status. Both reviews concluded that tea intake did not affect iron status in people with adequate iron stores.

Previous findings suggest that consumption of black tea reduces iron availability when examined under laboratory conditions. However, our analysis implies that this effect diminishes when determined in free-living subjects who do not necessarily drink their tea with their meals under the same conditions as during an experiment. A possible explanation for the discrepancy between conclusions from experimental and observational studies might be that results from single test meals do not reflect complete dietary patterns ${ }^{(39)}$. More extreme dietary differences than would be considered practical in the habitual diet can be implemented in the study design and results from test meals might therefore overestimate the importance of the effects of black tea on iron status. In a 16-week clinical trial investigating the possible differences between rooibos and black tea on the iron status of black South African school children, no difference was found between the actions of black tea in comparison to rooibos tea on markers of iron status ${ }^{(8)}$. These results suggest that black tea consumption with meals in the long term does not negatively affect parameters of iron status and supports the notion that results from single test meal studies may overstate the action of potential inhibitors of iron absorption on iron status.

In the present study polyphenol content of the black tea as well as tea intake in combination with other food items was not known. Cultural habits in South Africa show that tea is consumed both as a beverage between meals and as a drink accompanying meals ${ }^{(13)}$. Data from Kenya show that the majority of the Kenyan population consume tea with at least one meal ${ }^{(8,40)}$. At national level, tea is one of the five most commonly consumed foods in South Africa among children $^{(12)}$. A report on South African food consumption studies undertaken amongst different population groups shows that the dietary pattern among adults was similar ${ }^{(41)}$.

Temme \& Van Hoydonck ${ }^{(10)}$ mention that in populations with marginal iron status, defined as populations of children; of menstruating women (17-42 years); and of women of 19-43 years including a large percentage of iron-deficient women (16-40\%) there seems to be a negative association between tea consumption and iron status. Likewise, Nelson $\&$ Poulter $^{(38)}$ suggest that groups at risk of iron deficiency, described as children under 6 years; as adolescent girls; as women of age 18-49 years; and as women older than 75 years should not consume tea along with their meals. Although associations between tea consumption and iron status in children and elderly could not be determined with our data, we did not find any associations between black tea consumption and iron intake in several groups which are at risk for iron deficiency and iron deficiency anaemia.

Multiple regression analysis on women of menstruating age, which is one of the most cited examples of a population at risk, showed that black tea consumption did not contribute 
to an increased risk of iron deficiency or iron deficiency anaemia. Furthermore, also in sub-populations with a low iron intake or with depleted iron stores, no relation between black tea drinking and iron status was shown. Thus, the present results do not support the hypothesis that there is an association between black tea consumption and iron status in groups that are at high risk for iron deficiency.

\section{Conclusion}

Black tea consumption as part of a complete diet does not affect iron status in these black adult Africans, not even in sub-groups which are at a higher risk for iron deficiency.

Iron status of African adults was in general satisfactory in men, but iron deficiency was considerably prevalent in women. The likelihood of having iron deficiency or iron deficiency anaemia is not significantly explained by black tea consumption as part of a varied diet in this population. Therefore, we found no evidence that black tea consumption will have adverse effects on iron status populations at risk for iron deficiency or in populations with marginal iron status. Other strategies are urgently needed to address the high prevalence of iron deficiency in this group.

\section{Acknowledgements}

Biochemical analyses of serum were performed at the Department of Chemical Pathology, University of Pretoria. Financial support of the North-West (former Potchefstroom) University, the Foundation for Research Development, the Dry Bean Producers Organisation, Clover, the Medical Research Council and the South African Sugar Association is appreciated. We would like to acknowledge the efforts of Hester Vorster, who was the initiator and project manager of the THUSA study. We also thank Grieta Hanekom, Lizanne Muller and Machteld van Lieshout. P. S. H. performed statistical analysis and principally wrote the manuscript. J. C. J., T. H. and A. M.-B. contributed to the data analysis and writing of the paper. U. E. M. performed the field survey and prepared the dietary and nutritional information. None of the authors have any conflict of interest.

\section{References}

1. World Health Organization (2001) Iron Deficiency Anaemia. Assessment, Prevention and Control: A Guide for Programme Managers. Geneva: UNICEF/United Nations University/WHO.

2. Tapiero H, Gaté L \& Tew KD (2001) Iron: deficiencies and requirements. Biomed Pharmacother 55, 332.

3. McKay DL \& Blumberg JB (2002) The role of tea in human health: an update. $J$ Am Coll Nutr 21, 1-13.

4. Fairweather-Tait SJ \& Teucher B (2002) Iron and calcium bioavailability of fortified foods and dietary supplements. Nutr Rev 60, 360-367.

5. Hurrel RF, Reddy M \& Cook JD (1999) Inhibition of non-heme iron absorption in man by polyphenolic-containing beverages. Br J Nutr 81, 289-295.

6. Samman S, Sandström B, Toft MB, et al. (2001) Green tea or rosemary extract added to foods reduces nonheme-iron absorption. Am J Clin Nutr 73, 607-612.
7. Cook JD, Dassenko SA \& Lynch SR (1991) Assessment of the role of nonheme-iron availability in iron balance. Am J Clin Nutr 54, 717-722.

8. Breet P, Kruger HS, Jerling JC \& Oosthuizen W (2005) Actions of black tea and Rooibos on iron status of primary school children. Nutr Res 25, 983-994.

9. Marnewick JL, Joubert E, Swart P, Van der Westhuizen F \& Gelderblom WC (2003) Modulation of hepatic drug metabolizing enzymes and oxidative status by rooibos (Aspalathus linearis) and honeybush (Cyclopia intermedia), green and black (Camellia sinensis) teas in rats. J Agric Food Chem 51, $8113-8119$.

10. Temme EHM \& Van Hoydonck PGA (2002) Tea consumption and iron status. Eur J Clin Nutr 56, 379-386.

11. Vorster HH, Oosthuizen W, Jerling JC, Veldman FJ \& Burger HM (1997) The Nutritional Status of South Africans: A Review of the Literature from 1975-1996, pp. 13-20. Durban: Health System Trust.

12. Steyn HS \& Labadarios D (2000) Dietary Intake: 24-hour Recall Method. The National Food Consumption Survey (NFCS): Children Aged 1-9 Years, South Africa, 1999, pp. 218-311. Stellenbosch, South Africa.

13. MacIntyre UE (1998) Dietary intakes of Africans in transition in the North West Province. PhD Thesis, Department of Nutrition and Family Ecology, Potchefstroom University for Christian Higher Education.

14. Vorster HH, Wissing MP, Venter CS, et al. (2000) The impact of urbanization on physical, physiological and mental health of Africans in the North West Province of South Africa: the THUSA study. S Afr J Sci 96, 505-514.

15. Savarino A, Pescarmona GP \& Boelaert JR (1999) Iron metabolism and HIV infection: reciprocal interactions with potentially harmful consequences? Cell Biochem Func 17, 279-287.

16. Gordeuk VR, Delanghe JR, Langlois MR \& Boelaert JR (2001) Iron status and the outcome of HIV-infection: an overview. $J$ Clin Virol 20, 111-115.

17. MacIntyre UE, Venter CS \& Vorster HHA (2001) culture sensitive quantitative food frequency questionnaire used in an African population. I. Development and reproducibility. Publ Health Nutr 4, 53-62.

18. MacIntyre UE, Venter CS \& Vorster HHA (2001) culture sensitive quantitative food frequency questionnaire used in an African population. II. Relative validation by 7-day weighed food records and biomarkers. Publ Health Nutr 4, 63-71.

19. Venter CS, MacIntyre UE \& Vorster HH (2000) The development and testing of a food portion photograph book for use in an African population. J Hum Nutr Dietet 13, 205-218.

20. Bland JM \& Altman DG (1986) Statistical methods for assessing agreement between two methods of clinical measurement. Lancet 1(8476), 307-310.

21. US Department of Agriculture (2002) Dietary Reference Intakes. Washington, DC: Food and Nutrition Board, National Academy of Science.

22. Kumar R \& Singh M (1984) Tannins: their adverse role in ruminant nutrition. J Agric Food Chem 32, 447-453.

23. Hagerman AE \& Butler LG (1981) The specificity of proanthocyanidin-protein interactions. J Biol Chem 256, 4494-4497.

24. Lorenz M, Jochmann N, von KA, et al. (2007) Addition of milk prevents vascular protective effects of tea. Eur Heart $J \mathbf{2 8}$, 219-223.

25. Leenen R, Roodenburg AJ, Tijburg LB \& Wiseman SA (2000) A single dose of tea with or without milk increases plasma antioxidant activity in humans. Eur J Clin Nutr 54, 87-92.

26. Reddy V, Vidya Sagar G, Sreeramulu D, Venu L \& Raghunath M (2005) Addition of milk does not alter the antioxidant activity of black tea. Ann Nutr Metab 49, 189-195. 
27. Richelle M, Tavazzi I \& Offord E (2001) Comparison of the antioxidant activity of commonly consumed polyphenolic beverages (coffee, cocoa, and tea) prepared per cup serving. J Agric Food Chem 49, 3438-3442.

28. Hollman PC, Van Het Hof KH, Tijburg LB \& Katan MB (2001) Addition of milk does not affect the absorption of flavonols from tea in man. Free Radic Res 34, 297-300.

29. Kyle JA, Morrice PC, McNeill G \& Duthie GG (2007) Effects of infusion time and addition of milk on content and absorption of polyphenols from black tea. J Agric Food Chem 55, 4889-4894.

30. Hurrell RF, Reddy M \& Cook JD (1999) Inhibition of non-haem iron absorption in man by polyphenolic-containing beverages. Br J Nutr 81, 289-295.

31. Brune M, Rossander L \& Hallberg L (1989) Iron absorption and phenolic compounds: importance of different phenolic structures. Eur J Clin Nutr 43, 547-557.

32. Root MM, Hu J, Stephenson LS, Parker RS \& Campbell TC (1999) Iron status of middle-aged women in five counties of rural China. Eur J Clin Nutr 53, 199-206.

33. Gregory J, Foster K, Tyler H \& Wiseman M (1990) The Dietary and Nutritional Survey of British Adults. London: Her Majesty's Stationery Office.
34. Galan P, Yoon HC, Preziosi P, et al. (1998) Determining factors in the iron status of adult women in the SU.VI.MAX study. Eur J Clin Nutr 52, 383-388.

35. Ball MJ \& Bartlett MA (1999) Dietary intake and iron status of Australian vegetarian women. Am J Clin Nutr 70, 353-358.

36. Hunt JR \& Roughead ZK (1999) Nonheme-iron absorption, fecal ferritin excretion, and blood indexes of iron status in women consuming controlled lactoovovegetarian diets for $8 \mathrm{wk}$. Am J Clin Nutr 69, 944-952.

37. Mehta SW, Pritchard ME \& Stegman C (1992) Contribution of coffee, and tea to anemia among NHANES II participants. Nutr Res 12, 209-222.

38. Nelson M \& Poulter J (2004) Impact of tea drinking on iron status in the UK: a review. J Hum Nutr Diet 17, 43-54.

39. Hunt JR (2001) How important is dietary bioavailability? Am J Clin Nutr 73, 3-4.

40. Shell-Duncan B \& McDade T (2005) Cultural and environmental barriers to adequate iron intake among northern Kenyan schoolchildren. Food Nutr Bull 26, 39-48.

41. Nel JH \& Steyn NP (2002) Report on South African Food Consumption Studies Undertaken Amongst Different Population Groups (1983-2000): Average Intakes of Foods Most Commonly Consumed. Pretoria: Food Control, Department of Health. 